University at Albany, State University of New York

Scholars Archive

2-29-2012

\title{
Citation Help in Databases: The More Things Change, the More They Stay the Same
}

\author{
Mary Van Ullen \\ University at Albany, State University of New York, mvanullen@albany.edu \\ Jane Kessler \\ University at Albany, State University of New York, jkessler@albany.edu
}

Follow this and additional works at: https://scholarsarchive.library.albany.edu/ulib_fac_scholar

Part of the Information Literacy Commons

\section{Recommended Citation \\ Van Ullen, Mary and Kessler, Jane, "Citation Help in Databases: The More Things Change, the More They Stay the Same" (2012). University Libraries Faculty Scholarship. 29. \\ https://scholarsarchive.library.albany.edu/ulib_fac_scholar/29}

This Article is brought to you for free and open access by the University Libraries at Scholars Archive. It has been accepted for inclusion in University Libraries Faculty Scholarship by an authorized administrator of Scholars Archive. For more information, please contact scholarsarchive@albany.edu. 


\section{Citation Help in Databases: The More Things Change, the More They Stay the Same MARY VAN ULLEN}

University at Albany, Albany, New York, USA

JANE KESSLER

University at Albany, Albany, New York, USA

Address correspondence to Mary Van Ullen, University Library, University at Albany, 1400 Washington Ave., Albany, NY 12222 email mvanullen@uamail.albany.edu

In 2005 the authors reviewed citation help in databases and found an error rate of 4.4 errors per citation. This article describes a follow-up study which revealed a modest improvement in the error rate to 3.4 errors per citation, still unacceptably high. The most problematic area was retrieval statements. The authors conclude that librarians should include citation features in the evaluation of databases, and should open a dialogue with vendors about the importance of providing accurate, reliable information about citations to students.

KEYWORDS citations, citation generators, databases

\section{INTRODUCTION}

A much-discussed trait of the current generation of college students is their expectation for immediate, on-demand services. In an article on understanding this generation of students, Diana Oblinger (2003, p. 40) noted that "they expect that services will be available $24 \times 7$ in a variety of modes (Web, phone, in person) and that responses will be quick." In addition, students expect learning and information technology to be intertwined (Merritt, 2002). Libraries have responded in a variety of ways, such as keeping the library open longer, providing reference service via instant messaging, and having electronic resources available 24/7. 
Database vendors have responded to students' need for $24 \times 7$ support by enhancing databases with integrated online help, including help citing sources. As any public services academic librarian can attest, students often struggle with citation style and creating bibliographies. Because this information is found in databases provided by the library, students are likely to see it as credible and assume it is correct. In 2006, the authors examined the nature and accuracy of database citation help. Results of that study revealed diversity in the quality and quantity of the citation help in popular academic databases, with an overall disappointingly high level of inaccuracy (Kessler and Van Ullen).

Since that time, many databases have added additional citation features, such as a function for generating bibliographies from selected records. In addition, database vendors have had time to refine the citation help provided and to reflect changes in bibliographic styles. For these reasons, a follow-up study was performed to see if the accuracy of citation help in databases had improved.

\section{LITERATURE REVIEW}

In a report on the growth of citation software leases to academic institutions, Vincent Kiernan (2006) noted that while libraries often recognize the value of such programs in controlling plagiarism, the cost is prohibitive for some libraries. Given the current economic climate, that may be increasingly true. Thus, librarians should welcome improvements in citation formatting in research databases for which they are already spending a significant proportion of their collections budget.

Little has been written about citation formatting in databases. Justine I. Martin (2009) surveyed college faculty about their attitudes toward computer-generated citations. Her study did not 
focus exclusively on citations created within research databases, but included all types of electronically-generated citations. Martin found a low level of instructor awareness about the existence of citation generating software or citation creation within databases. Faculty participating in this study tended to view certain types of bibliographic errors, such as missing data, more seriously than formatting mistakes, a fact that database vendors may wish to consider.

Connie Jo Ury (2009) surveyed academic librarians concerning the type of student support and instruction about citation practice provided by their institutions. Ury's survey did not include questions about database-generated citations. However, four percent of librarians who completed the survey instrument commented that their institution relied on database citations, and twelve percent provided access to citation software.

The library may not be the only unit on campus helping students with citation practice. In some cases, students may seek assistance from the writing center. Susan Mueller (2009) of the St. Louis College of Pharmacy's Writing Center examined automatically generated citations from an EBSCO and a ProQuest database. She reviewed a small number of citations from each of the two databases in MLA, APA and AMA styles, and found an unacceptable error rate in all cases. Mueller proposed a strategy for using database-generated citations as a teaching tool for writing center tutors to use with students, which may also be of interest to librarians. While Mueller addressed database generated citations, her study was limited to two databases and a small number of citations.

\section{METHODOLOGY}

Twelve databases offered at many undergraduate libraries were examined for help with citing sources. Of these, six were also examined in the earlier study: EBSCO Academic Search 
Premier, Credo (previously XReferPlus), ScienceDirect, CSA Sociological Abstracts, Wilson Education Full Text, and LexisNexis Academic. The authors no longer had access to one of the databases from the previous study, Gale InfoTrac OneFile, so it was not included. In addition to the six from the previous study, three additional databases (ArticleFirst, Proquest Criminal Justice Periodicals Index, and Scopus), two journal collections (JSTOR and Project Muse), and one reference ebook collection (Oxford Reference Online) were examined.

The databases were examined for the type of information available and the answers to the following questions were recorded:

- Was citation help available?

- Where was the citation help located?

- Did the citation help include general information on citation styles and citing sources?

- Did the citation help include sample citations?

- What citation styles were covered?

- Were the appropriate style manuals referenced?

- Was there a disclaimer about the limitations of the citation help?

- Were pre-formatted citations provided?

- Was there a citations-on-demand feature that creates citations and bibliographies for a marked set of records?

- Was there an export to EndNote or RefWorks option?

- Was the digital object identifier (doi) included in bibliographic records?

Citation help was considered to be one of four types: general information about citation styles, examples, pre-formatted citations, or a citations-on-demand feature. Pre-formatted citations are 
defined as those that are included as part of the bibliographic record and are presented in all styles supported by the database: the user does not need to specify a particular style. A citations-on-demand feature, such as QuikBib in CSA databases, allows users to generate citations by selecting one or more records and a specific citation style.

If both a citations-on-demand feature and pre-formatted citations were available, only the citations-on- demand were included in the study by performing searches and selecting five citations in both APA and MLA styles. This was the case for EBSCO Academic Search Premier, Wilson Education Full Text and Criminal Justice Periodicals Index. For Scopus and Sociological Abstracts, which offered only a citations-on-demand feature, searches were performed, five citations were created in both APA and MLA styles and these were the citations used for analysis. Four databases (Credo, ArticleFirst, Project Muse, and Oxford Reference Online) only offered pre-formatted citations. Five citations in MLA and APA style were selected from each of these databases. This generated 90 citations for review: 45 in APA style and 45 in MLA style.

In addition, if the database offered general examples in the citation help, these were also reviewed for accuracy in the same manner and the results recorded in a separate spreadsheet. There were 17 general examples located in four databases (Wilson Education Full Text, Project Muse, Proquest Criminial Justice Periodical Index, and Scopus). In all, a total of 107 citations were reviewed.

The citations were reviewed for accuracy using the edition of the style manual for the style specified by the database. If no edition was specified, the authors used the most current edition at the time of writing: The Publication Manual of the American Psychological Association, $5^{\text {th }}$ edition, in conjunction with the APA Style Guide to Electronic References, and the MLA 
Handbook for Writers of Research Papers, $6^{\text {th }}$ edition. A description of each error found was recorded in a spreadsheet, along with the database name and the citation style. Errors were also categorized into one of the following categories: punctuation, capitalization, use of italics/underlining, names, date, syntax, and retrieval statement. As in the previous study, a syntax error was considered "an error in which the order of the elements in the citation was incorrect, elements were missing, or elements were present in the citation that should not have been" and a retrieval statement error was "any omission, incorrect placement, or improper inclusion of information about online sources (such as the date accessed, database name, url, or library where accessed.)" (Kessler and Van Ullen, 2006, p. 25)

\section{RESULTS}

\section{Overview of Database Citation Features}

\section{Academic Search Complete}

The help file for Academic Search Premier was common to many other popular EBSCO databases. It contained examples for the following styles: AMA, APA, Chicago: Author-Date, Chicago: Humanities, MLA and Vancouver/ICMJE. The help page for each style contained a reference to the appropriate manual and a disclaimer to consult the library for more guidance. This database contained files of downloadable images taken from articles in the databases, and the help file included instructions on how to cite the images for each of the six styles. The help file also contained a short list of commonly used terms related to citation practice as well as a brief bibliography of suggested readings on citation conventions, including several style manuals.

Pre-formatted citations were available in each record. Clicking on the "Cite This Article" button brought up a screen giving the citation in all of the six supported styles. Users could cut and paste the citations into a document. 
Users could also work with multiple saved records to create citations-on-demand. Selected items could be stored in a folder. Users could choose a method of output (print, save, email), and then select a style to create citations. There was an option to sort the items in the folder by name, although it is unclear how that sort was performed, because the results did not appear alphabetically by the author's last name. The output had a disclaimer to consult the database citation help and to correct any mistakes if needed, and was labeled "References "or "Works Cited." After the list of formatted citations, there was a list of persistent links back to the original database records, which a student would need to remove to create a bibliography.

In addition to allowing for direct export to EndNote or Refworks, Academic Search Complete also worked with EndNote Web, ProCite, CITAVI, or Reference Manager. Users could also save citations formatted in XML, BibTeX or MARC21 format.

\section{Education Full Text/WilsonWeb}

The help file was common to WilsonWeb databases, and it linked to a "How to Cite an Article" page, WilsonWeb's style guide. The "How to Cite an Article" page stated that it would provide examples of citing full-text of a WilsonWeb periodical article, full-text of an entry from a WilsonWeb biographical profile and a full-text periodical article from a WilsonDisc (CD-ROM) database in APA and MLA formats. It actually also included examples of citing an open access article, and an image for these two styles. In addition, a full-text periodical example of both Chicago/Turabian Humanities and Author-Date styles was provided. Also included were examples of citing journal articles and book reviews using the Bluebook, a guide for legal materials. The guide mentioned AMA as a style of possible interest, but did not provide a reference or examples. 
From the individual record level, the user was given the option to print, email, save, cite or export. The first three options did not allow the user to specify a citation format. When the cite option was selected, a pre-formatted citation was given in MLA, APA, Chicago/Turabian: Humanities and Chicago/Turabian: Author-Date styles. At the bottom of this screen there was a link to the "How to Cite an Article" page on WilsonWeb.

If a user wanted to format a number of citations at once to generate a bibliography, a menu bar on the screen offers adjacent print/email/save and exporting/citing tabs, both of which led to the same screen. When printing, emailing or saving, the user was given the choice of selecting MLA, APA, Chicago/Turabian: Humanities, Chicago/Turabian: Author-Date or HTML formats. The results were not alphabetized. The user could also export records to RefWorks, EndNote, or other bibliographic software.

\section{Lexis-Nexis Academic}

At the time the data was gathered, the help file in this database provided no information on citing sources. Output options did not include citation formatting. Users could export records to RefWorks. Subsequently, LexisNexis has added help via a wiki which includes an article on citing references. Examples of citations are provided in APA, MLA and Chicago/Turabian styles for some of the common document types found in LexisNexis Academic. Because this wiki was introduced after the data was gathered, the examples were not included in this analysis.

\section{Project Muse}


A brief article entitled "How to Cite Articles in Project MUSE" could be found by looking in the help file under "Training and Promotional Materials." While the database offered pre-formatted citations in MLA, APA, and Chicago, this article only covered MLA and APA styles. It showed the general format for journal articles for these two styles, followed by one specific example each. The article referred users to the manuals for more information.

To locate pre-formatted citations, users had to go into the individual record, and then click on a "summary" link in order to see another link to view the pre-formatted citation. The citations could be copied for inclusion in a bibliography. Each style had a disclaimer to check for accuracy and a link to the help file. Users could also save selected records from a results list to a file, export the file to e-mail, RefWorks, or EndNote, or print it, but there was no option to export formatted citations.

\section{ScienceDirect}

The ScienceDirect help file did not offer information about citation formatting, nor did the database generate citations in any particular style. Citations could be exported in ASCII, BibTeX, RIS, or RefWorks formats. The help file stated that ScienceDirect was unable to offer assistance with using export software and instructed the user to contact his own institution's information technology office.

\section{Sociological Abstracts/CSA}

The help file was generic to the CSA platform, and only contained information about the mechanics of downloading data and not about citation formatting in general. Marked records could be saved to a folder and printed, emailed or saved, or the QuikBib feature could be used to create a bibliography in text or html. Citations could be formatted in several styles: APA, 
AMA, ASA, Chicago Author-Date, CBE, Harvard, MLA, Turabian and Uniform. Multiple editions were available for some bibliographic styles. The bibliography page contained a warning to check for accuracy, as well as a link to a page entitled "Output Style Instructions" with some information about the style chosen. This page included links to the website for the selected citation style, sample citations for a book and a journal article, and links to several academic libraries' style guides. Unfortunately, several of the style guide links were broken.

Reference lists generated for some styles were not alphabetized. Users also had the option to export results to RefWorks.

\section{Credo Reference}

Credo Reference provided pre-formatted citations at the bottom of each full-text entry. The citations were available in APA, Chicago, Harvard and MLA styles. Users could also export bibliographic information to EndNote, ProCite, Reference Manager and RefWorks. There was no other information about citing sources available.

\section{Oxford Reference Online}

Like Credo Reference, Oxford Reference Online provided pre-formatted citations at the bottom of each full-text entry, labeled "How to Cite This Entry." Only one citation was provided, and there was no indication of the citation style used, nor was it obvious what style had been used. Therefore, these citations were not analyzed for errors. The Oxford Reference Online help file contained a section on citing sources, which focused on how to provide the URL for an entry, and made no mention of citation styles. This database did not allow for export of citations.

\section{ArticleFirst}

The help file for ArticleFirst was generic to the FirstSearch platform. Information in the help file about citing sources was limited to a discussion of the export feature. 
Each bibliographic record in ArticleFirst contained a "Cite This Item" link. Clicking on the link took the user to a page with citations for the item in four styles: APA, Chicago (author-date), Harvard, and MLA. At the bottom of the citation page, there were links to the WorldCat records for the four style manuals. Additionally, there was a disclaimer warning users that style requirements vary and that they should follow the specific requirements of their publisher, institution or organization. There was also a caution that text formatting within citations may be lost or altered when copied into word processing programs or Web-based applications such as e-mail services. There was no option to create a bibliography.

ArticleFirst also had an export feature for use with an individual record or multiple records. Users could export bibliographic records directly to Endnote or Refworks, or create a text file for use with other bibliographic software.

\section{Scopus}

There was no general information about citation styles or citing sources provided in Scopus.

The QuikBib feature was provided under the output function. QuikBib created citations and bibliographies in eight styles: APA, BibTeX, CBE, Chicago, Harvard, Harvard British Standard, MLA, NLM, Turabian, and Uniform. Bibliographies could be created in HTML, RTF or text formats. The bibliography page generated in QuikBib was similar to that in Sociological Abstracts.

Also under the output function, Scopus users could directly export bibliographic records to RefWorks, and could export in RIS format to EndNote, ProCite and Reference Manager, or as a comma separated file to Excel. 


\section{ProQuest Criminal Justice Periodicals Index}

In the help file for the Proquest interface, there was no general information about citation styles. There was a "Cite a Document" section under "Document View" and an "Exporting Citations" section under "Managing Documents." The "Cite a Document" explained the "Cite This" feature available in the record.

The "Cite This" feature was available in each bibliographic record. It provided a pre-formatted citation that could be copied and pasted into a bibliography. Styles available were APA, MLA, AMA, Chicago - Humanities, Chicago- Author/Date, and Vancouver. The citation page included the citation, a link to the web site for the style selected, a warning to review the formatting of author names and dates and that missing information may need to be supplied, and a link to a page with general examples for the selected style.

Users could also select multiple citations and create a bibliography that could be emailed, printed or downloaded by using the "Cite" link at the top of the results list. In addition to a link to the web site for the style selected and a warning to review the citations, the bibliography page included general formats and examples for several type of documents found in the database, such as scholarly journal articles, magazines, and dissertations.

In the results list, users could also select multiple citations for export directly to RefWorks, EndNote, ProCite, and Reference Manager, or download a text file that is compatible with these programs.

\section{JSTOR}

JSTOR did not provide any information about citation styles or citing sources in the help file. Neither a citations-on-demand feature nor pre-formatted citations were available. 
JSTOR provided an export feature for EndNote, ProCite, Reference Manager, and BibTeX. Each article had an "Export This Citation" link. Users could select multiple articles, save them to MyJSTOR and then export all at once. This feature was covered in the Help file under "Using MyJSTOR and Citation Management."

\section{Error Rates}

Table 1 shows the number of general examples found in Wilson Education Full Text, Project Muse, Proquest Criminal Justice Periodical Index, and Scopus, along with the number and type of errors and the errors per example. The remaining databases in the study did not provide general examples in the citation help.

Insert table 1 here.

There were 59 errors in 17 example citations, resulting in a mean of 3.5 errors per example. Only one citation example, the APA citation from Scopus, did not contain any errors. The number of errors per citation ranged from a high of 4.75 for Project Muse to a low of .5 for Scopus. Nearly half the errors were in the retrieval statement. There were more errors in APA citations than in MLA citations.

Table 2 shows the number and type of errors in the citations selected for review as well as the number of errors per citation. The citations selected for review were from pre-formatted citations or the citations-on-demand feature of the databases. Although 90 citations were selected for review, only 80 are listed in Table 2 because the 10 citations from Oxford Reference Online were in a generic style and were not able to be analyzed for errors.

Insert Table 2 here. 
The 80 selected citations contained a total of 266 errors, resulting in a mean number of errors per citation of 3.3. All 80 citations contained at least one error. The number of errors per citation ranged from a high of 5 for Project Muse to a low of 1.8 for ArticleFirst. As with example citations, retrieval statements contained the most errors. Errors in MLA citations accounted for $52 \%$ of all errors.

\section{Location of Help}

In order for citation help to be effective, it must be easily located by users. The location of citation help varies among databases and depends on the type of citation help (general information, general examples, pre-formatted citations, or citations-on-demand.) General information, when provided, was linked in all cases from the main search screen. General examples were found in two places: the help files and the bibliography created by the citationson-demand feature. In all cases where pre-formatted citations were available, they were found at the individual record level. This location seems logical because the citation will appear at the point of need. Citations-on-demand, when available, were found in the output (print, save, email) feature of the databases reviewed.

\section{References to Sources of Style Information}

Some of the databases reviewed (ScienceDirect, LexisNexis Academic, Oxford Reference Online, and JSTOR) do not refer users to style guides. EBSCO Academic Search Premier provides references to the style section of both the MLA and APA web sites as well as the appropriate style manuals. Other databases reviewed either referred users to the organizations' web sites or did not supply a complete citation to the appropriate style manuals.

\section{DISCUSSION}

With the passage of time, the proliferation of electronic resources, and the growth of distance learning, students have increased expectations of $24 / 7$ help in conducting their research, including help with citing sources. In 2006 when the authors examined the citation help 
available in databases, the quality of the help was disappointing. The previous study found that $94 \%$ of the citation examples examined had errors (Kessler and Van Ullen, 2006). A significant improvement was expected in this follow-up study.

In the first study, seven databases were examined: EBSCO Academic Search Premier, Gale Infotrac OneFile, XReferPlus, ScienceDirect, Sociological Abstracts (CSA), Wilson Education Full Text, and LexisNexis Academic. Citations were reviewed for four styles: APA, MLA, Chicago, Turabian. In the current study, 12 databases were examined: EBSCO Academic Search Premier, Credo (formerly XReferPlus), ScienceDirect, Sociological Abstracts (CSA), Wilson Education Full Text, LexisNexis Academic, ArticleFirst, Project Muse, Scopus, Proquest Criminal Justice Periodical Index, JSTOR, and Oxford Reference Online. APA and MLA citations were reviewed.

In this present study, the overall error rate (including examples, pre-formatted citations and citations-on-demand) was 3.4 errors per citation versus an error rate of 4.4 errors per citation in the prior study (Kessler and Van Ullen, 2006). However, these results are not directly comparable as some of the databases examined varied between the two studies. Three of the databases examined in both studies showed a decrease in the number of errors per citation (EBSCO Academic Search Premier, Credo, and Sociological Abstracts.) One database, Wilson Education Full Text, showed an increase in the number of errors per citation. A comparison could not be made for LexisNexis Academic, because examples were not included in the study.

In both studies, the retrieval statements and syntax were the top two sources of errors. Punctuation was the next most frequent category of error in the pre-formatted citations and citations-on-demand, followed by italics/underlining, capitalization, names, and dates. In the 
examples, capitalization was the next most frequent category of error, followed by italics/underlining, punctuation, and names.

\section{Retrieval Statements}

Retrieval statements are notoriously difficult because of the variety of sources from which online articles can originate. In addition, both styles seem to be evolving as to how to best handle citations for online sources. The $7^{\text {th }}$ edition of the MLA Handbook for Writers of Research Papers was published in March of 2009 and contained significant changes to the rules for citing online sources. In 2007, APA published The APA Style Guide to Electronic References which distinguished between articles with a doi assigned and those without. Then in July of 2009 , the $6^{\text {th }}$ edition of the Publication Manual of the American Psychological Association was published. Lewis (2008) notes some problems with the approach taken to citing articles in the $6^{\text {th }}$ edition, saying "Now not only will librarians and faculty be teaching their students a new style that is quirky and detail-oriented, they will also be telling them to search for the dois, article URLs, and journal homepage URLs to cite articles accessed in research databases. This process seems very untenable indeed, especially for undergraduates" (p. 129). In addition, the initial printing of the $6^{\text {th }}$ edition was riddled with errors, introducing more confusion into the citation process.

Database vendors/producers have tended not to handle revisions to the style guides in a timely manner. For example, the citation below from EBSCO Academic Search Premier in MLA style was found in April of 2009 and is not correct under either the $6^{\text {th }}$ or $7^{\text {th }}$ edition of the MLA Handbook for Writers of Research Papers.

The $6^{\text {th }}$ edition calls for using the url of the service homepage, but EBSCO provides the url of the article (Modern Language Association of America, 2003, p. 229). The $7^{\text {th }}$ edition requires the title of database, medium of publication, but no url (Modern Language Association of 
America, 2009, p. 192). Below are the correct general formats from each edition and the actual citation from EBSCO.

$7^{\text {th }}$ edition format:

Author name (Last name, first name). "Title of Article" Title of Journal Volume. Issue (Year): page range. Title of Database. Medium of Publication. Date of Access written as Day Month Year.

$6^{\text {th }}$ edition format:

Author name (Last name, first name). "Title of Article" Title of Journal Volume. Issue (Year): page range. Title of Database. Library Name. City. Date of Access written as Day Month Year. $<$ url of service homepage $>$.

Citation from EBSCO Academic Search Premier:

Deakins, Eric. "Helping students value cultural diversity through research-based teaching." Higher Education Research \& Development. 28.2 (June 2009): 209-226. Academic Search Premier. EBSCO. [Library name], [City], [State abbreviation]. 2 Apr. 2009 $<$ http://search.EBSCOhost.com/login.aspx?direct=true\&db=aph\&AN=37139758\&site=ehostlives.

Likewise, databases had similar problems with the changes to retrieval statements in APA style. For example, there are separate formats for articles with a doi assigned and those without. The format for an article with a doi assigned, the bibliographic record from an article in Project Muse showing the doi, and the APA example citation from Project Muse's "How to Cite Articles in Project Muse" are shown below.

APA Format for article with doi assigned: 
Last name, First initial. (Year). Article title. Journal Title, volume(issue), page range. doi:

Bibliographic record from Project Muse showing doi was available:

Arnoldian Humanism, or Amnesia and Autobiography in the Schwarzenegger Action

Film

Grady, Frank.

Cinema Journal, 42, Number 2, Winter 2003, pp. 41-56 (Article)

DOI: $10.1353 / c j .2003 .0003$

HTML Version | PDF Version (279k) | Summary

From "How to Cite Articles in Project Muse"

Example: Grady, Frank. (2003). Arnoldian Humanism, or Amnesia and Autobiography in the

Schwarzenegger Action Film. Cinema Journal, 42(2), 41-56. Retrieved September 4, 2004 from Project MUSE database.

The retrieval statement in this example is correct based on $5^{\text {th }}$ edition of the Publication Manual of the American Psychological Association (although other elements of the citation are not correct according to the $5^{\text {th }}$ edition.) However, this example was present in September of 2009. The Style Guide to Electronic References was published in 2007, ample time to correct the examples. 
One retrieval statement error that appeared in both studies is that retrieval statements are frequently included for articles that are not available full-text in the database. This error was found in databases with some full-text (EBSCO Academic Search Premier, Wilson Education Full Text, Proquest Criminal Justice Periodicals Index, and CSA Sociological Abstracts) as well as one with no full-text (Scopus.) On one level, it is easy to understand that this problem is a difficult one for database vendors to handle because the same database may be available with different full-text options. For example, EBSCO Academic Search is available in Elite, Premier and Complete versions, each with varying amounts of full-text. However, database vendors should develop an approach to generating citations that incorporates this complexity. At a minimum, users should be warned about the issue.

\section{Other Types of Errors}

Many of the other types of errors are closely related. These errors stem from the failure of the programming used to generate the citations to select the proper information from the database record, or from the inadequacy of the information in the database record. An example of the errors introduced by programming was found in Project Muse. The author's birth date is included with their name in some bibliographic records in this database. In these cases, the birth year also incorrectly appeared in the generated citation. Another example was found in Sociological Abstracts, where the journal name, although present in the bibliographic record, did not appear in the APA citation.

The information in the bibliographic record can be inadequate for the needs of a particular citation style.

A common error found in MLA style citations was the use of initials instead of the author's first name. This error seemed to be a result of the author's first name not being available in the bibliographic record. Another error of this type was found in Proquest Criminal Justice Periodicals Index. Because only the first page an 18 page article was listed in the bibliographic 
record, the article appeared to be only one page long in the citation. At a minimum, database vendors should alert users to these systematic problems because every citation generated will be incorrect. To prevent these types of errors, database vendors should give consideration to capturing sufficient information, such as author full names and complete page ranges, in the bibliographic record to support the common citation styles.

Many of the other errors found were entirely preventable and seem to be the result of lack of attention to detail in programming. For example, in both studies, the number of punctuation and capitalization errors was surprisingly high, since for both styles the rules are unambiguous. Problems with recognizing proper names are to be expected, but that accounted for only a few capitalization errors. APA style requires only the first word of the article title and subtitle and any proper nouns to be capitalized, yet many citations had all significant words capitalized. There were also many errors categorized as italics/underlining, particularly in MLA style, which may be the result of the change to italicizing instead of underlining journal titles. Again, this is a result of lack of attention to detail and easily corrected.

While it is more complicated to create a program to dynamically generate perfectly accurate citations, it is unacceptable to find errors in static general examples which are created by the database vendor to provide guidance to users. It still seems to be the case, as the authors noted in the last study, that "it is apparent that much of this information was put together hastily, without reference to the style manuals or any proofreading" (Kessler and Van Ullen, 2006, p. 41). Below is an example from Wilson Education Full Text "How to Cite Articles" in which the specific example does not follow the format of the general example immediately above. The 
general example calls for the article title to be in initial capitals, but the specific example only has the first word of the article title capitalized.

Citing a Full Text periodical article in the MLA style, for aggregated databases (a simplified adaptation). Double space, indent 2nd and subsequent lines 5 spaces.

Author \#1- Last Name, First Name/initials, Author \#2 and more - First Name/Initials, Last Name, and Final Author - First Name/Initials, and Last Name. "Article Title." Journal/Magazine Title volume number.issue number (publication year): page numbers. Database name. Web.. Date accessed.

Example:

Kean, Rita, LuAnn Gaskil, Larry Leistritz. "Effects of community characteristics, business environment, and competitive strategies on rural retail business performance." Journal of Small Business Management 36.2 (1998): 45-57. Wilson OmniFile Full Text, Mega Edition. Web. 10 Jan. 2005.

Databases using utilities like QuikBib need to exercise caution that the information provided to users is accurate for the specific database. In Scopus and CSA Sociological Abstracts, after a bibliography is generated using the QuikBib feature, the bibliography includes a link to "output style instructions." In the example below, the output style instructions provide examples of citations from articles in Psyclnfo, which is present in the retrieval statements. This could be very confusing for students who may not understand the differences between databases. This type of information should be customized to the particular database.

Journal Example from Scopus Output Style Instructions: 
Head, D. (2003). Child's play: Revisiting play in early childhood settings. Journal of

Family Studies, 9(2), 275. Retrieved May 1, 2004, from the PsycINFO Database.

\section{CONCLUSION}

There seems to be a trend among the more widely-used academic databases, such as EBSCO Academic Search and Wilson Education Full Text, to include pre-formatted citations and citations-on-demand. Particularly noteworthy database enhancements include easily accessible pre-formatted citations and the ability to generate a bibliography for a list of selected records. Because citing sources is a challenge for students, having citation help at the point of the need adds value to the databases. However, while there was a modest improvement in accuracy overall, the error rates for the databases examined are still unacceptably high.

Unfortunately, citation help in these databases continues to be compiled with little attention to detail. Multiple errors in each citation are completely unacceptable because citations are all about the details. Many of the errors are in elements of the citation for which formatting is straightforward, such as capitalization, italics, and underlining. While the formatting of other elements, such as the retrieval statement, are more complex, improved accuracy would be possible with more focus on the issue.

To improve the quality of citation help, vendors should examine the database features through the eyes of a student. This could be done through focus groups, basic usability testing, or even careful editing. The process should be examined from start to finish: doing a search, selecting records, viewing pre-formatted citations, or creating a bibliography. The output should be meticulously compared to the standard style guides. In addition, the online help files should be examined for accuracy and ease of use. Vendors would be well-advised to consult with 
librarians, who help students with citation issues on a regular basis, to design features that meet student needs and are accurate.

Librarians should include citation features in the evaluation of databases. In a time of limited resources, librarians must insist that libraries receive value for the features for which they are paying. Librarians should open a dialogue with vendors about the importance of providing accurate, reliable information about citations to students.

Given that improvements in citation help have been disappointing over the past five years, this topic requires further monitoring. With the difficult economic climate, libraries may have difficulty justifying the purchase of citation management software. One possible area for further research would be a comparison of the accuracy of citations created by a citation management software, such as RefWorks or EndNote, with that of citations produced by the databases themselves.

\section{References}

American Psychological Association. (2010). Publication Manual of the American Psychological Association (6 $6^{\text {th }}$ edition). Washington, DC: American Psychological Association.

American Psychological Association (2001). Publication Manual of the American Psychological Association (5 ${ }^{\text {th }}$ edition). Washington, DC: American Psychological Association.

American Psychological Association. (2007). APA Style Guide to Electronic References. Washington, DC: American Psychological Association. 
American Psychological Association. (2009). Corrections to the First Printing of the Publication Manual of the American Psychological Association, $6^{\text {th }}$ edition. Retrieved from http://supp.apa.org/style/PM6E-1st-Printing-Reprint-Corrections.pdf

Kessler, J., \& Van Ullen, M.K. (2006). Citation help in databases: Helpful or harmful? Public Services Quarterly 2, 21-42. doi:10.1300/J295v02n01_03

Kiernan, V. (2006, June 9). Toss out the index cards. Chronicle of Higher Education, A29-A30. Retrieved from http://chronicle.com/

Lewis, L.A. (2008). From the front lines: An academic librarian reports on the impact of APA's new electronic reference guidelines. Reference \& User Services Quarterly 48, 128-131. Retrieved from http://www.rusq.org/

Martin, J.L. (2009). Course instructor perceptions of computer-generated bibliographic citations. Reference Services Review 37, 304-312. doi:10.1108/00907320910982794

Merritt, S.B., \& Neville Editor, S. (2002). Generation Y: A perspective on America's next generation and their impact on higher education. The Serials Librarian 42, 41-50. doi:10.1300/J123v42n01_06

Modern Language Association of America. (2009). MLA Handbook for Writers of Research Papers ( $7^{\text {th }}$ edition). New York: Modern Language Association of America.

Modern Language Association of America. (2003). MLA Handbook for Writers of Research Papers ( $6^{\text {th }}$ edition). New York: Modern Language Association of America. 
Mueller, S. (2009). Database citation generators: Generating what, exactly? Writing Lab Newsletter 33, 6-10. Retrieved from http://www.writinglabnewsletter.org/

Oblinger, D. (2003). Boomers, Gen-Xers, \& Millenials: Understanding the "new students." Educause Review 38, 37-47. Retrieved from http://www.educause.edu/er

Ury, C.J., \& Wyatt, P. (2009). What we do the for sake of correct citations. In Ury, C.J. (Ed.), Brick and Click Libraries: Proceedings of an Academic Library Symposium ( $9^{\text {th }}$, Maryville, Missouri). Retrieved from ERIC database. (ED507380) 